
\title{
25 Research Soure \\ The Upside: Coping and Psychological Resilience in Australian Adolescents During the COVID-19 Pandemic
}

Joanne R Beames ( $\sim$ j.beames@blackdog.org.au )

Black Dog Institute, University of New South Wales https://orcid.org/0000-0003-3630-0980

\section{Sophie H Li}

Black Dog Institute

Jill M Newby

Black Dog Institute, University of New South Wales

Kate Maston

Black Dog Institute

\section{Helen Christensen}

Black Dog Institute, University of New South Wales

Aliza Werner-Seidler

Black Dog Institute, University of New South Wales

\section{Research Article}

Keywords: resilience, coping, adolescent, youth mental health, Covid-19, pandemic

Posted Date: August 26th, 2021

DOl: https://doi.org/10.21203/rs.3.rs-820688/v1

License: (9) (i) This work is licensed under a Creative Commons Attribution 4.0 International License. Read Full License

Version of Record: A version of this preprint was published at Child and Adolescent Psychiatry and Mental Health on December 1st, 2021. See the published version at https://doi.org/10.1186/s13034-02100432-z. 


\section{Abstract}

Background: Since the COVID-19 outbreak, few studies have investigated the positive psychological consequences on young people. This study examined resilience, positive experiences, and coping strategies reported by Australian adolescents during COVID-19.

Methods: Self-report surveys were administered online to a sample of 760 Australian adolescents aged 12-18 years. Quantitative and qualitative methods were used to assess resilience, positive experiences, and coping strategies. Regression analyses were conducted to explore the relationship between resilience and demographics and mental illness history, as well as between resilience and positive experiences.

Results: Overall, adolescents were somewhat resilient $(M=20.93, S D=8.29)$. They reported positive experiences during COVID-19, including increased empathy, compassion, gratitude, and connection with others, and reported using a range of active coping strategies. Having a mental illness history and identification as female or non-binary gender were associated with lower resilience ( $B s>2.82, p s<.001)$. Further, resilience was associated with decreased psychological distress $(O R=0.89, p<.001)$ and with increased positive experiences (ORs $>1.03, p s<.001)$.

Conclusions: Our results indicate that Australian adolescents commonly reported positive experiences and used active coping strategies during COVID-19. Some young people demonstrated higher levels of resilience and were able to make the most out of an unpredictable situation that severely disrupted their daily routine. Resilience-building programs for adolescents may be effective in increasing adaptability after adversity (e.g., climate change, bushfires, pandemics).

\section{Background}

The COVID-19 pandemic has had a profound effect on adolescents around the world (1). Young people have experienced disruptions to their education, social connections, family relationships, future job opportunities, financial stability, and mental health. These negative consequences have been documented in a growing number of cross-sectional and longitudinal surveys, with the overwhelming consensus being that the mental health of adolescents has deteriorated during the pandemic $(1-3)$. However, it is unknown whether adolescents have demonstrated psychological resilience, experienced any positive effects, or used effective coping strategies during COVID-19. Understanding how adolescents have coped will facilitate disaster planning by guiding ways to optimise social resources and enhance psychological resilience (4).

Psychological resilience refers to the maintenance or recovery of mental health after times of adversity (5-7). According to the developmental systems perspective, adaptive capacity depends on multiple interacting systems (e.g., 8, 9-11). For example, a young person is embedded in systems such as family and school, which are, in turn, embedded in higher order systems such as community and economies. The systems perspective hypothesises that the process of adaptation depends on the capacity of these systems to adapt in response to threat. The shift toward the systems perspective was largely influenced 
by the growing threat of mass-trauma global adversities, including terror attacks, natural environmental disasters, and pandemics $(9,12)$. In the current paper, we focus on the individual level. We answer questions about how young people coped during the COVID-19 outbreak and investigate factors or processes that support adaptive success (8). Individual-level factors that promote resilience in adolescents include age and gender, as well as active coping strategies, hope, and optimism $(7,13)$. Overall, individuals show varying levels of resilience in response to stressful life events (8).

The use of effective coping skills to regulate emotional experiences during, or after, adversity is an example of an adaptive process underpinning resilience (7). Coping skills can be conceptualised in different ways (14), including differentiating between active (or approach) and passive (or avoidant) coping skills. Active coping involves using cognitive and behavioural strategies to directly reduce or control stress, such as problem-solving, seeking social support, and cognitive restructuring, whereas passive coping involves avoiding or disengaging from sources of stress (15). In general, active coping strategies are related to better adjustment to stress and improved mental health compared to passive strategies $(15,16)$. Similarly, research has also shown that active coping strategies, such as problemsolving and social support seeking, are important in the transition from adolescence to early adulthood (17). Taken together, this research indicates that the use of active coping skills may be indicative of resilience in response to COVID-19.

Several international studies have examined youth resilience in the context of COVID-19. One crosssectional survey study with Chinese youth conducted in April 2020 found that trait resilience and use of positive coping strategies were related to decreased depression and anxiety (18). Positive coping encompassed active (rather than passive) strategies, including cognitive reappraisal, problem-solving, and help-seeking. Converging results have been found in the Unites States and Europe, with young people reportedly using social connection, relaxation, staying busy, hobbies, watching television or playing video games, and maintaining a routine as ways to cope (19-22). Another survey study with young adults $\left(M_{\mathrm{age}}=22\right)$ in Zurich, similarly identified that coping strategies, such as keeping a daily routine, physical activity, contacting friends and family, acceptance of the COVID-19 crisis, and cognitive restructuring, were associated with reduced distress during the pandemic (23). The results of these studies show the beneficial effects of resilience processes on youth mental health during COVID-19. It remains unknown whether similar benefits were experienced by young Australians, during a later phase of the pandemic that included stringent lockdowns.

The relevance of resilience processes in the context of COVID-19 is underscored by an emerging adult literature. Global studies show that engagement in active coping strategies, such as recreational activity, acceptance, and perspective taking, were associated with lower symptoms of depression, anxiety, and stress in during COVID-19 $(24,25)$. Results from a New Zealand adult sample also show pandemic 'silver linings' including a sense of community and social cohesion, improved social relationships, personal reflection, personal development, and perceived agency (26). Together, these results indicate that the effect of COVID-19 may not be inherently or exclusively negative and that some individuals may be more likely to experience positive outcomes than others. Further investigation is needed to determine whether 
these findings generalise to adolescents, a group that typically undergoes a unique set of developmental changes and major life transitions.

\section{The Current Study}

The potential positive aspects of young people's experience during COVID-19 in the Australian context is unknown. Further, limited attention has been given to individual differences in resilience and the relationship between resilience and positive and negative experiences during the pandemic. We addressed these gaps by conducting a large cross-sectional, mixed methods survey study to investigate resilience, positive experiences, and coping strategies in Australian adolescents during COVID-19. In line with process-oriented resilience frameworks (7), including the developmental systems perspective (8), resilience was conceptualised as a dynamic process of adaptation.

The aims of this mixed-methods study were two-fold. The first aim was to explore resilience, positive experiences, and active coping strategies in Australian adolescents between 12-18 years. For the qualitative component, young people were asked to answer open-ended questions about coping strategies employed during the pandemic. Based on previous studies from the youth and adult literature during COVID-19 $(18,19,21,24)$, we expected that adolescents would report positive experiences and engagement in primarily active (versus passive) coping strategies. The second aim was to investigate associations between resilience and demographic characteristics (age, gender, mental illness history), distress, and positive experiences. Given the early stage of COVID-19 research in youth sample, our analysis of the associations between resilience and other variables were exploratory.

\section{Method}

\section{Participants}

Young people between the ages of 12-18 years were recruited across Australia via social media advertisements. Data was collected from an online survey between the end of June 2020 and the beginning of August 2020. This period of data collection included the relaxing of lockdown restrictions across Australia, with the exception of the city of Melbourne and the state of Victoria (both were subject to restrictive second wave lockdown conditions during this time). Data reported here were collected as part of a larger survey examining the impact of COVID-19 on the lives and mental health of Australian adolescents, which is documented elsewhere (27).

\section{Measures}

Demographics and mental illness history. Information was collected on participants' age and gender. For mental illness history, participants were also asked whether they had ever been diagnosed with depression or anxiety by a professional ( $0=$ no, $1=$ yes, depression only, $2=$ yes, anxiety only, $3=$ yes, both depression and anxiety, $4=1$ don't know, 5 = prefer not to say). 
Resilience. The 10-item Connor-Davidson Resilience Scale (CD-RISC-10) was used to measure resilience (28). The CD-RISC-10 assesses the availability of resilience factors, such as social support and selfefficacy, to maintain or regain mental health despite adversity. Each item is rated on a five-point scale ranging from $0=$ not true at all, $1=$ rarely true, $2=$ sometimes true, $3=$ often true, and $4=$ true nearly all of the time. Total scores are calculated by summing all items, with a higher score indicating higher resilience. Scores range from $0-40$. The CD-RISC-10 has demonstrated reliability and validity among adolescent samples $(29,30)$. There are no defined cut-off scores for the scale, however normative data indicated that the mean resilience score in an international adolescent sample was 24.7 (31). To the best of our knowledge, normative data for the CD-RISC-10 for Australian adolescents are not yet available.

Psychological distress. The Kessler-6 (K6) assessed general psychological distress over the past 30 days $(32,33)$. Each item is rated on a 5-point scale ranging from $1=$ none of the time, $2=$ a little of the time, $3=$ some of the time, $4=$ most of the time, $5=$ all of the time. Total scores are calculated by summing all items, with a higher score indicating higher psychological distress. Scores range from 6-30. Consistent with recommended cut-off scores, responses were then binarised into no probable mental illness (scores $6-18)$ and probable mental illness $(19-30 ; 34)$. The $K 6$ has been widely used and validated with young people and has strong psychometric properties (35-38). Overall, the $\mathrm{K} 6$ is appropriate to measure adolescent distress in large surveys.

Positive experiences. A bespoke questionnaire developed by the authors for the current study was used to assess positive experiences during COVID-19, based on previous literature $(39,40)$. Participants were presented with a list of five positive experiences, including: "feeling more connected with friends and family", "feeling things are more calm at home", "feeling more grateful", "feeling kinder and more generous towards others", and "feeling more empathy towards others who are less fortunate than you". Participants were asked to indicate whether they had experienced any of these outcomes in the past week by selecting a check box.

Coping strategies. Participants were asked to write free text responses to one open-ended question that enquired about coping strategies used during COVID-19 (i.e., "What strategies have you used to cope?"). Responses were optional and not required to complete the survey.

\section{Procedure}

Participants were directed to the online survey platform (Qualtrics) after clicking on study advertisements. All respondents were required to demonstrate that they understood the study and had the capacity to provide informed consent, using the Gillick Competency Task (41), before providing consent and accessing the survey. Upon completion of the survey, participants were placed into a draw to receive one of five AUD $\$ 50$ vouchers. The study was approved by the UNSW Human Research Ethics Committee (HC200334).

\section{Statistical Analysis}




\section{Quantitative Analyses}

All quantitative analyses were conducted in SPSS v. 25. Descriptive analyses were used to report demographic and sample characteristics, and the proportion of young people who endorsed each positive experience during the pandemic.

A simultaneous multiple regression analysis was conducted to explore the relationship between individual difference characteristics and resilience. Resilience was regressed on age, gender, and mental illness history (i.e., a previous diagnosis of depression and/or anxiety). Gender and mental illness history were entered into the model using dummy $\operatorname{codes}(0=$ male, $1=$ female; $2=$ non-binary $/$ other; $0=$ no diagnosis; 1 = diagnosis). Unstandardised regression coefficients were used to describe the effects. Squared semi-partial correlations were examined to further understand the unique relationships between the variables within the model.

A binary logistic regression analysis was conducted to explore the relationship between resilience and psychological distress $(0=$ no probable mental illness, $1=$ probable mental illness $)$. For this analysis, resilience was regressed on psychological distress. A series of binary logistic regression analyses were then conducted to explore the relationship between resilience and each positive experience (e.g., increased empathy; $0=$ No, $1=$ Yes). For these analyses, positive experiences were regressed on resilience. Unstandardised estimates were exponentiated into odds ratios. All regression assumptions, including normality, homoscedasticity, linearity, and multicollinearity were met within the relevant models.

Excluding outliers in the regression analyses did not change the pattern of results, and so all outliers are included in the results below.

\section{Qualitative Analyses}

Coding strategy. All qualitative analyses were conducted in Excel. One author (JRB) coded responses to the open-ended question using a deductive approach. JRB developed a code book based on coping strategies typically defined as "active" and "passive" in the coping literature (42), as well as coping strategies identified in previous COVID-19 research $(18,23)$. JRB refined the codes through repeated immersion with the responses. In line with the study aim, focus was given to positive or helpful strategies rather than those that were clearly maladaptive or harmful, such as self-harm. Passive strategies were coded when they were described as alleviating emotional distress or promoting positive emotions, even if only in the short term. This approach aligns with emerging research that indicates that coping or emotion regulation strategies are not inherently maladaptive or adaptive (43). A second author (SL) applied the code book to $20 \%$ of the responses to check coding alignment. There was high agreement between both coders $(90 \%)$ and all discrepancies were resolved through discussion.

\section{Results}

\section{Sample Characteristics}


The final sample included 760 young people aged between 12 and 18 years, with a mean age of 14.8 years $(S D=1.26)$. A majority were female $(72 \%)$, spoke English at home $(87.7 \%)$ and born in Australia (88.1\%). Participants lived across all Australian states and territories. Approximately $50 \%$ indicated that their parent or carer's job had been impacted by the pandemic. Just over $35 \%$ of the sample reported being diagnosed with anxiety and/or depression in the past. The mean score on the K6 was 18.08 ( $S D=$ 6.63; range 6-30). Almost half of the sample (48.5\%) scored above the threshold that indicates psychological distress indicative of probable mental illness. For more detailed characteristics of the sample, see (27).

\section{Analyses}

Resilience. The mean level of resilience reported by young people was $20.93(S D=8.29$, range $=0-40)$.

Individual differences in resilience. A simultaneous multiple linear regression was run to explore the relationship between resilience and age, gender, and mental illness history (i.e., a previous diagnosis of depression and/or anxiety). The overall model was significant, $F(4,656)=23.31, p<.001, R^{2}=12.4 \%$. Female gender, non-binary gender, and mental illness history explained a significant proportion of the variance in resilience $(p s<.001)$, whereas age did not $(p=.31)$. Young people who identified as female and young people who identified as non-binary or another gender reported significantly lower resilience levels than young people who identified as male. Young people with a mental illness history reported significantly lower resilience compared to those without a mental illness history. Squared semi-partial correlations indicated that mental illness history $\left(s r^{2}=.067 ; 6.76 \%\right)$ accounted for a greater unique proportion of the variance in resilience compared to age $\left(s r^{2}=.0014 ; .14 \%\right)$ and the gender variables $\left(s r^{2}\right.$ $<.022 ;<2.2 \%)$. See Table 1 for regression model output.

Table 1 Linear regression results for resilience

\begin{tabular}{|c|c|c|c|c|c|c|c|c|}
\hline \multirow{3}{*}{ 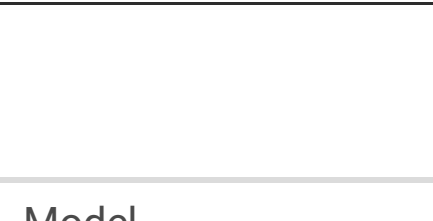 } & \multirow{2}{*}{$B$} & \multicolumn{2}{|c|}{$95 \%$ Cl for $B$} & \multirow[t]{2}{*}{$S E B$} & \multirow[t]{2}{*}{$\beta$} & \multirow[t]{2}{*}{$t$} & \multirow[t]{2}{*}{$p$} & \multirow[t]{2}{*}{$R^{2}$} \\
\hline & & $L L$ & UL & & & & & \\
\hline & & & & & & & & .12 \\
\hline Constant & 29.31 & 21.94 & 36.68 & 3.75 & & 7.81 & .00 & \\
\hline Age & -0.25 & -0.74 & 0.23 & 0.25 & -0.04 & -1.02 & .31 & \\
\hline Female & -2.83 & -4.39 & -1.27 & 0.79 & -0.15 & -3.57 & $.00 *$ & \\
\hline Non-binary & -5.35 & -7.94 & -2.75 & 1.32 & -0.17 & -4.05 & $.00 *$ & \\
\hline Mental illness history & -4.61 & -5.88 & -3.34 & 0.65 & -0.27 & -7.13 & $.00 *$ & \\
\hline $\begin{array}{l}\text { Note. } B=\text { unstandardis } \\
\text { limit; } S E B=\text { standard } \\
R^{2}=\text { coefficient of dete }\end{array}$ & $\begin{array}{l}\text { ressiol } \\
\text { or the u } \\
\text { tion. }{ }^{*}\end{array}$ & $\begin{array}{l}\text { efficie } \\
\text { andard } \\
\text { D01. }\end{array}$ & $\begin{array}{l}l=\text { col } \\
\text { coeff }\end{array}$ & $\begin{array}{l}\text { רce in } \\
; ; \beta=s\end{array}$ & $\begin{array}{l}\text { al; } L L \\
\text { idardi }\end{array}$ & $\begin{array}{l}\text { Dwer lir } \\
\text { regres }\end{array}$ & $\begin{array}{l}U L= \\
\mathrm{n} \mathrm{coe}\end{array}$ & \\
\hline
\end{tabular}


Resilience and psychological distress. A binary logistic regression was run to explore the relationship between resilience and psychological distress. The overall model was significant, $\chi^{2}(1)=134.92, p<.001$, and explained 22\% (Nagelkerke $R^{2}$ ) of the variance in distress. Young people who reported higher resilience had lower odds of reporting probable mental illness compared to young people who reported higher resilience $(O R=.89, p<.001)$. See Table 2 for regression model output.

Table 2 Logistic regression for psychological distress

\begin{tabular}{|c|c|c|c|c|}
\hline & \multirow[t]{2}{*}{$O R$} & \multicolumn{2}{|c|}{$95 \% \mathrm{Cl}$ for $O R$} & \multirow[t]{2}{*}{$p$} \\
\hline & & $L L$ & $U L$ & \\
\hline Resilience & 0.89 & 0.87 & 0.91 & $.00 *$ \\
\hline Constant & 11.03 & & & .00 \\
\hline
\end{tabular}

Positive experiences. Over half of the sample (56.9\%) reported feeling greater levels of empathy toward others who are less fortunate than themselves, and $42.9 \%$ reported feeling more grateful in general. Approximately one-third of the sample reported feeling more connected with friends and family (34\%) and feeling kinder and more generous toward others (32.1\%). In comparison to these positive experiences, experiencing feelings that things were calmer at home was endorsed by fewer young people (23\%). Further, the logistic regression models indicated that resilience was significantly related each type of positive experience, $O R s>1.03, p s<.001$. For example, young people with higher resilience also had higher odds of feeling more connected to friends and family compared to those who did not report feeling more connected. The amount of variance explained by each positive experience was low and variable, ranging from $2.3 \%-9.5 \%$. See Table 3 for the regression model output.

Table 3 Logistic regressions for positive experiences 


\begin{tabular}{|c|c|c|c|c|}
\hline & \multirow[t]{2}{*}{$O R$} & \multicolumn{2}{|c|}{$95 \% \mathrm{Cl}$ for $\mathrm{OR}$} & \multirow[t]{2}{*}{$p$} \\
\hline & & $L L$ & UL & \\
\hline \multicolumn{5}{|c|}{ Feeling connected } \\
\hline Resilience & 1.06 & 1.04 & 1.08 & $.00 *$ \\
\hline Constant & 0.14 & & & .00 \\
\hline \multicolumn{5}{|c|}{ Calm at home } \\
\hline Resilience & 1.04 & 1.02 & 1.08 & $.00 *$ \\
\hline Constant & 0.12 & & & .00 \\
\hline \multicolumn{5}{|c|}{ Feeling grateful } \\
\hline Resilience & 1.07 & 1.05 & 1.09 & $.00 *$ \\
\hline Constant & 0.17 & & & .00 \\
\hline \multicolumn{5}{|c|}{ Feeling kind/generous } \\
\hline Resilience & 1.05 & 1.03 & 1.07 & $.00 *$ \\
\hline Constant & 0.18 & & & .00 \\
\hline \multicolumn{5}{|c|}{ Feeling empathy } \\
\hline Resilience & 1.03 & 1.01 & 1.05 & $.00 *$ \\
\hline Constant & 0.69 & & & .07 \\
\hline
\end{tabular}

Coping strategies. The coding of free-text responses to the question assessing coping strategies resulted in 16 categories. Of these categories, 14 were of active coping strategies and 2 were of passive coping strategies. See Table 4 for a summary of descriptive statistics for all categories reported and Table 5 for definitions and example quotes.

A total of 596 (78.42\%) young people provided a response to the open-ended coping strategies question. Of these, $475(79.70 \%)$ responses were coded as coping strategies that had the potential for positive effects on mental health and wellbeing. The total number of coping strategies used ranged between 1-4, with a mean of $1.40(S D=0.67)$. The most common coping strategies were active, including socialising (37.89\%), engaging in hobbies (24.4\%), and doing physical exercise (12.63\%). Other active coping strategies reported included using psychological strategies such as perspective taking and relaxation (8.84\%), keeping a routine ( $7.16 \%)$, focusing on the positives (6.53\%), and help-seeking (5.68\%). Overall, passive coping strategies, including distraction (10.74\%) and sleeping or relaxing/sleeping $(6.11 \%)$, were less frequently reported than active coping strategies. 
Table 4 Summary of descriptive statistics for coded coping strategies

\begin{tabular}{|lll|}
\hline Coping strategy & $\boldsymbol{n}$ & $\%$ \\
\hline Active & & \\
\hline Socialising & 180 & 37.89 \\
\hline Hobbies & 116 & 24.42 \\
\hline Physical exercise & 60 & 12.63 \\
\hline Psychological strategies & 42 & 8.84 \\
\hline Routine & 34 & 7.16 \\
\hline Focusing on the positives & 31 & 6.53 \\
\hline Help-seeking & 27 & 5.68 \\
\hline Emotional expression & 21 & 4.42 \\
\hline Psychological treatment/therapy & 21 & 4.42 \\
\hline Time for self & 11 & 2.32 \\
\hline Limit screen time & 6 & 1.26 \\
\hline Spirituality/Religion & 4 & 0.84 \\
\hline Being informed & 3 & 0.63 \\
\hline Humour & 2 & 0.42 \\
\hline Passive & 51 & 10.74 \\
\hline Distraction & 29 & 6.11 \\
\hline Rest/Sleep/Relax & & \\
\hline
\end{tabular}

Table 5 Summary of categories in open-ended responses about coping strategies used during COVID-19 


\begin{tabular}{|c|c|c|}
\hline Coping strategy & Definition & Example \\
\hline \multicolumn{3}{|l|}{ Active } \\
\hline \multirow[t]{2}{*}{ Socialising } & \multirow{2}{*}{$\begin{array}{l}\text { Talking, hanging out, or connecting with } \\
\text { family or friends (face-to-face or using } \\
\text { technology). }\end{array}$} & $\begin{array}{l}\text { "Talking to friends and } \\
\text { family" }\end{array}$ \\
\hline & & $\begin{array}{l}\text { "I video call my friends in } \\
\text { some of my classes and after } \\
\text { school so I'm not lonely. We } \\
\text { often do schoolwork, } \\
\text { homework, exercise/workouts } \\
\text { or just hang out" }\end{array}$ \\
\hline \multirow[t]{2}{*}{ Hobbies } & \multirow[t]{2}{*}{$\begin{array}{l}\text { Any kind of activity enacted for enjoyment, } \\
\text { pleasure, or achievement, such as listening to } \\
\text { music, art, reading, or gaming. }\end{array}$} & $\begin{array}{l}\text { "Doing what i like, my } \\
\text { hobbies. drawing, dancing, } \\
\text { music, eating" }\end{array}$ \\
\hline & & $\begin{array}{l}\text { "Indulging myself in activities } \\
\text { I enjoy, like music and } \\
\text { gaming" }\end{array}$ \\
\hline \multirow[t]{2}{*}{ Physical exercise } & \multirow{2}{*}{$\begin{array}{l}\text { Any kind of physical activity, such as team } \\
\text { sports, walking, running, yoga, or other } \\
\text { references to working out. }\end{array}$} & $\begin{array}{l}\text { "Going outside and } \\
\text { exercising" }\end{array}$ \\
\hline & & "Walking a few hours a day" \\
\hline \multirow[t]{2}{*}{$\begin{array}{l}\text { Psychological } \\
\text { strategies }\end{array}$} & \multirow[t]{2}{*}{$\begin{array}{l}\text { Active coping strategies, such as breathing, } \\
\text { perspective taking, using calm/relaxation } \\
\text { apps, and meditation. }\end{array}$} & $\begin{array}{l}\text { "I have used breathing } \\
\text { exercises to calm myself } \\
\text { down" }\end{array}$ \\
\hline & & $\begin{array}{l}\text { "I tried most of the anxiety } \\
\text { strategies I leant [sic] when I } \\
\text { saw a psychologist last year } \\
\text { (eg. Socratic questions, } \\
\text { meditation, staying in the } \\
\text { moment, etc.)" }\end{array}$ \\
\hline Routine & $\begin{array}{l}\text { Deliberate engagement in regular activities, } \\
\text { such as schoolwork/study (or returning to } \\
\text { school), making plans and to-do lists, basic } \\
\text { hygiene (e.g., brushing teeth, getting dressed), } \\
\text { or daily chores (e.g., making bed), eating } \\
\text { healthily. }\end{array}$ & $\begin{array}{l}\text { Having a schedule especially } \\
\text { with school work, arranging } \\
\text { them into hours of the day } \\
\text { and giving myself breaks in } \\
\text { between }\end{array}$ \\
\hline \multirow{2}{*}{$\begin{array}{l}\text { Focusing on the } \\
\text { positives }\end{array}$} & \multirow{2}{*}{$\begin{array}{l}\text { Taking a positive outlook on the current } \\
\text { situation and the future, or other references to } \\
\text { doing the best that they can }\end{array}$} & "I try to stay optimistic" \\
\hline & & $\begin{array}{l}\text { "Just saying it will be okay, } \\
\text { you can make it. This will be } \\
\text { better soon" }\end{array}$ \\
\hline \multirow[t]{2}{*}{ Help-seeking } & \multirow[t]{2}{*}{$\begin{array}{l}\text { Asking for help from friends, family, teachers, } \\
\text { or professionals, including broad references } \\
\text { to talking to other people about problems. }\end{array}$} & $\begin{array}{l}\text { "I've been talking to my } \\
\text { parents more (about mental } \\
\text { health) and I've found that } \\
\text { this helps" }\end{array}$ \\
\hline & & $\begin{array}{l}\text { "I spoke to a teacher that I } \\
\text { have for multiple classes } \\
\text { ab[out] a couple of the things }\end{array}$ \\
\hline
\end{tabular}


I've been struggling with after I had a incident in her class"
Emotional Outward displays of emotions to self or to others (e.g., crying), including through
expression drawing/writing.

"Honestly l've just cried a lot"

"I have a sketch book where I draw my emotions and thoughts"

"I've been seeing a psychologist"

"Talking to my therapist"

$\begin{array}{ll}\text { Time for self } & \text { Taking time out to reset and spending time } \\ \text { on own (but not explicitly framed as a way to } \\ \text { avoid problems). }\end{array}$

Seeing a mental health professional for support and/or engaging in therapy

treatment/therapy

(including counselling, psychologists, medications).

"Spending time to concentrate on a particular task, and chilling for my own self"

Limit screen time

Restricting the amount of time spent using technology.

"I have set myself up a screen time limit to reduce my screen time"

Spirituality/religion

Any reference to religion, spirituality, or God.

"Have faith in God"

"Reading my bible"

Being informed

Staying up to date with information about COVID-19.

"Watching the news so I knew exactly what was going on and no one else was telling me false stuff"

Humour

Any reference to humour.

"Humour"

Passive

Distraction

Deliberately not paying attention or trying to distract from the current situation, or other references to keeping busy (includes TV/Netflix/YouTube).

Rest/Sleep/Relax

Any mention of resting, sleeping, napping, or relaxing (coded as separate to routine when identified as a coping strategy to boost functioning, rather than maintaining regular sleep/wake cycles).

\section{Discussion}

To the best of our knowledge, this study is the first to explore the positive aspects of young people's psychological experience during COVID-19 within the Australian context. Our results add to the emerging literature showing that the experience of young people during COVID-19 is not exclusively negative, and that positive experiences are common. 
Resilience levels in our sample were slightly lower than normative levels reported in an international sample with a similar age range before COVID-19 (31). Levels were also lower than a large representative Australian study of older adolescents between 16-17 years (i.e., 26.5; 44). Increased psychological distress has been demonstrated in young people during COVID-19 (e.g., 2, 27). Given our finding that there is a negative relationship between resilience and distress, it is not surprising that resilience levels in our sample of young people were comparatively reduced overall during the pandemic. Young people are vulnerable to stressors relating to family, friends, and schools (45), all of which have been significantly disrupted by COVID-19. Our results also indicated that some young people were more resilient than others. Identifying those with increased vulnerability will be important to aid optimal recovery in response to future stressors (e.g., climate change, pandemics, bushfires). Resilience-building programs are one way to facilitate adaptive functioning in the face of adversity. Resilience-building interventions generally aim to strengthen protective factors (6), which can be internal (e.g., coping skills) or external (e.g., family relationships, community support and available services). Many resilience-based approaches are now available, with increasing evidence that they help to prevent decline or regain psychological functioning in adolescence after adversity (46-48).

In our sample of young people, mental illness history was more strongly related to resilience compared to age and gender. This finding corresponds to prior COVID-19 research in young people showing that mental health history is related to higher distress $(18,27)$. Young people with a mental illness history may be more vulnerable to increased threat caused by COVID-19. Vulnerability may be explained by having fewer skills to manage distress and facilitate adaptation, or by an inability to use acquired coping skills effectively when the broader system is threatened. This interpretation aligns with research showing that effective emotion regulation is dependent on context (49), with flexible selection and timing of strategy use linked to better emotional outcomes (e.g., 43, 50).

One resilience-building skill that might facilitate bouncing back from adversity is active coping. Evidence for the use and effectiveness of active coping strategies during COVID-19 has been documented in previous research $(18,19,23)$, which we replicated in our cross-sectional study. We found that the most reported strategies were socialising, engaging in hobbies, and exercise. These findings emphasise the importance of peer relationships for young people (51), as well as their capacity to engage in activities that potentially enhance positive mood. We also found evidence for the use of passive coping strategies, including distraction and sleep or relaxing. Although our cross-sectional findings cannot extrapolate causality, based on the resilience framework (7), the use of coping strategies likely increases the likelihood of positive adaptation.

In addition to coping strategies, other important psychosocial resilience factors include optimism and hope (52). Adolescents in our sample reported feeling more empathy, gratitude, connectedness, and kinder, more generous feelings toward others. Increased resilience was associated with these positive experiences, converging with other research that has linked challenging experiences with wellbeing and reduced psychopathology (53). These results are also consistent with findings that adults have the capacity to experience 'silver linings' and unexpected positive outcomes in the midst of the COVID-19 
pandemic (26). Future research is needed to determine whether positive experiences can be sustained, and whether adolescents with an affinity for focusing on the positives are more resilient than those who do not (or vice versa).

Our exploratory results indicate that gender might influence vulnerability to adversity and, by extension, capacity for positive experiences. Young people who identified as female or non-binary/another gender reported significantly lower resilience. Although a comparison to pre-pandemic levels was not available, this general pattern of results is consistent with prior research $(18,54,55)$. Given that young females have higher rates of mental health problems, particularly internalising disorders such as anxiety and depression, they may be more vulnerable during prolonged stressors. Gender differences in resilience are not well understood and further research is needed to explore how gender affects vulnerability to and recovery after stressful life events. Identifying vulnerable individuals who are struggling to cope will help allocate mental health resources to those that need them most in the aftermath of COVID-19.

\section{Limitations}

The current study had several limitations. We used a convenience sample of young people that was recruited online using established networks within the Black Dog Institute. Although this approach facilitated timely administration and data collection, which was necessary in the context of a rapidly evolving public health disaster, selection bias may limit generalisability to the broader population of Australian young people. For example, $72 \%$ of our sample were female. Sampling methods have been identified as a critical issue in COVID-19 research (56).

Another limitation was that our data collection methods relied on retrospective self-reports and openended responses from young people. This methodology is susceptible to response bias, such as social desirability, which can occur even when surveys are anonymous. Integration of other perspectives, such as from parents, school teachers, or school counsellors/psychologists, and validated measures (e.g., of coping strategies or positive experiences) might help to corroborate reports from young people and increase reliability of findings. Our approach is credible, however, as evidenced by alignment of findings from our qualitative and quantitative data sources, as well as with previous research.

Finally, this study was cross-sectional and correlational. This design means that causal conclusions cannot be made about resilience, coping, and other positive outcomes, nor about the long-term positive effects of COVID-19 on Australian youth. There is a pressing need for prospective longitudinal resilience studies (7) that assess multiple developmental systems (e.g., individual, family, and economic; 13). Assessing multiple levels has the advantage of documenting cascading consequences, whether positive or negative, of large-scale environmental stressors such as COVID-19. Understanding the full impact of COVID-19 is critical to developing effective mental health disaster readiness and response plans for young people.

\section{Conclusions}


Our study showed that, during the COVID-19 pandemic, young Australians have demonstrated resilience, albeit some more than others, as well as the capacity for positive experiences. Our study also showed that a large proportion of young people reported using active coping strategies during the rapidly evolving, unpredictable circumstances that they found themselves in. Building on prior work, our results indicate that resilience and distress are important targets for youth psychological intervention in public health emergencies such as pandemics. A major question for public health authorities is how to improve and prepare young people for a response to ongoing pandemics, as well as future pandemics, disasters and other impending crises driven by climate change. Clearly a psychological disaster plan is needed. Drawing upon the strengths of young people and incorporating capacity building before disaster strikes is likely to increase their likelihood of responding with resilience. A systems-level approach that helps young people to focus on the positives and to build a repertoire of coping strategies is needed to maximise beneficial outcomes for young people in the long-term following pandemics.

\section{Abbreviations}

CD-RISC-10: 10-item Connor-Davidson Resilience Scale

K6: Kessler-6 Scale

\section{Declarations}

\section{Ethics Approval and Consent to Participate:}

The study was approved by the University of New South Wales Human Research Ethics Committee (HC200334). Informed consent was obtained from all individual participants included in the study.

\section{Consent for Publication:}

All participants consented for non-identifiable data to be published.

\section{Availability of Data and Material:}

Not publicly available due to the sensitive nature of the data and ethical guidelines.

\section{Competing Interests:}

None to declare.

\section{Funding:}

This study was supported by the Black Dog Institute, a NSW Health Fellowship awarded to AW-S, a MRFF Career Development Fellowship awarded to JN, and an NHMRC Senior Principal Fellowship (115614) awarded to HC. The funders had no role in the study design, collection, analysis or interpretation of the data, writing the manuscript, or the decision to submit the paper for publication. 


\section{Author Contributions:}

All authors contributed to the study conception and design. Material preparation and data collection was performed by AW-S. Quantitative data analysis was performed by JRB. Qualitative coding was completed by JRB and SL. The first draft of the manuscript was written by JRB, with support from AW-S. All authors commented on previous versions of the manuscript. All authors read and approved the final manuscript.

\section{Acknowledgements:}

Sincere thanks to all the study participants for taking part in this survey. Thanks also to lana Wong for assisting with Qualtrics programming, to Dr Samantha Spanos for survey testing.

\section{References}

1. de Miranda DM, da Silva Athanasio B, Sena Oliveira AC, Simoes-e-Silva AC. How is covid-19 pandemic impacting mental health of children and adolescents? International Journal of Disaster Risk Reduction. 2020;51:101845.

2. Racine N, Cooke JE, Eirich R, Korczak DJ, McArthur B, Madigan S. Child and adolescent mental illness during covid-19: A rapid review. Psychiatry Research. 2020;292:113307.

3. Guessoum SB, Lachal J, Radjack R, Carretier E, Minassian S, Benoit L, et al. Adolescent psychiatric disorders during the covid-19 pandemic and lockdown. Psychiatry Research. 2020;291:113264.

4. Holmes EA, O'Connor RC, Perry VH, Tracey I, Wessely S, Arseneault L, et al. Multidisciplinary research priorities for the covid-19 pandemic: A call for action for mental health science. The Lancet Psychiatry. 2020;7:547.

5. Masten AS. Ordinary magic. Resilience processes in development. The American Psychologist. 2001;56:227.

6. Luthar SS, Cicchetti D, Becker B. The construct of resilience: A critical evaluation and guidelines for future work. Child Development. 2000;71:543.

7. Kalisch R, Baker DG, Basten U, Boks MP, Bonanno GA, Brummelman E, et al. The resilience framework as a strategy to combat stress-related disorders. Nature Human Behaviour. 2017;1:784.

8. Masten AS. Resilience in developmental systems: Principles, pathways, and protective processes in research and practice. Multisystemic resilience. New York: Oxford University Press; 2021.

9. Masten AS. Global perspectives on resilience in children and youth. Child Development. 2014;85:6.

10. Masten AS. Resilience in children threatened by extreme adversity: Frameworks for research, practice, and translational synergy. Development and Psychopathology. 2011;23:493.

11. Masten AS. Resilience in developing systems: Progress and promise as the fourth wave rises. Development and Psychopathology. 2007;19:921.

12. Masten AS, Narayan AJ. Child development in the context of disaster, war, and terrorism: Pathways of risk and resilience. Annual Review of Psychology. 2012;63:227. 
13. Masten AS, Motti-Stefanidi F. Multisystem resilience for children and youth in disaster: Reflections in the context of covid-19. Adversity and Resilience Science. 2020;1:95.

14. Skinner EA, Edge K, Altman J, Sherwood H. Searching for the structure of coping: A review and critique of category systems for classifying ways of coping. Psychological Bulletin. 2003;129:216.

15. Zimmer-Gembeck MJ, Skinner EA. The development of coping: Implications for psychopathology and resilience. Developmental Psychopathology. 2016;4:1.

16. Compas BE, Jaser SS, Bettis AH, Watson KH, Gruhn MA, Dunbar JP, et al. Coping, emotion regulation, and psychopathology in childhood and adolescence: A meta-analysis and narrative review. Psychological Bulletin. 2017;143:939.

17. Leipold B, Munz M, Michéle-Malkowsky A. Coping and resilience in the transition to adulthood. Emerging Adulthood. 2019;7:12.

18. Zhang C, Ye M, Fu Y, Yang M, Luo F, Yuan J, et al. The psychological impact of the covid-19 pandemic on teenagers in china. Journal of Adolescent Health. 2020.

19. Waselewski EA, Waselewski ME, Chang T. Needs and coping behaviors of youth in the U.S. during covid-19. Journal of Adolescent Health. 2020;67:649.

20. Janssen LHC, Kullberg M-LJ, Verkuil B, van Zwieten N, Wever MCM, van Houtum LAEM, et al. Does the covid-19 pandemic impact parents' and adolescents' well-being? An ema-study on daily affect and parenting. PLoS ONE. 2020;15:e0240962.

21. Commodari E, La Rosa VL. Adolescents in quarantine during covid-19 pandemic in italy: Perceived health risk, beliefs, psychological experiences and expectations for the future. Frontiers in Psychology. 2020;11.

22. Branquinho C, Kelly C, Arevalo LC, Santos A, Gaspar de Matos M. "Hey, we also have something to say": A qualitative study of portuguese adolescents' and young people's experiences under covid-19. Journal of Community Psychology. 2020;48:2740.

23. Shanahan L, Steinhoff A, Bechtiger L, Murray AL, Nivette A, Hepp U, et al. Emotional distress in young adults during the covid-19 pandemic: Evidence of risk and resilience from a longitudinal cohort study. Psychological Medicine. 2020:1.

24. Jungmann SM, Witthöft M. Health anxiety, cyberchondria, and coping in the current covid-19 pandemic: Which factors are related to coronavirus anxiety? Journal of Anxiety Disorders. 2020;73:102239.

25. Khan AH, Sultana MS, Hossain S, Hasan MT, Ahmed HU, Sikder MT. The impact of covid-19 pandemic on mental health \& wellbeing among home-quarantined bangladeshi students: A crosssectional pilot study. Journal of Affective Disorders. 2020;277:121.

26. Jenkins M, Hoek J, Jenkin G, Gendall P, Stanley J, Beaglehole B, et al. Silver linings of the covid-19 lockdown in new zealand. PLoS ONE. 2021;16:e0249678.

27. Li SH, Beames JR, Newby JM, Maston K, Christensen H, Werner-Seidler A. The impact of covid-19 on the lives and mental health of australian adolescents. European Child \& Adolescent Psychiatry. 2021. 
28. Campbell-Sills L, Stein MB. Psychometric analysis and refinement of the connor-davidson resilience scale (cd-risc): Validation of a 10-item measure of resilience. Journal of Traumatic Stress. 2007;20:1019.

29. Yu X-n, Lau JTF, Mak WWS, Zhang J, Lui WWS, Zhang J. Factor structure and psychometric properties of the connor-davidson resilience scale among chinese adolescents. Comprehensive Psychiatry. 2011; 52:218.

30. Duong C, Hurst CP. Reliability and validity of the khmer version of the 10-item connor-davidson resilience scale (kh-cd-risc10) in cambodian adolescents. BMC Res Notes. 2016;9:297.

31. She R, Yang X, Lau MMC, Lau JTF. Psychometric properties and normative data of the 10-item connor-davidson resilience scale among chinese adolescent students in hong kong. Child Psychiatry \& Human Development. 2020;51:925.

32. Kessler RC, Andrews G, Colpe LJ, Hiripi E, Mroczek DK, Normand SLT, et al. Short screening scales to monitor population prevalences and trends in non-specific psychological distress. Psychological Medicine. 2002;32:959.

33. Kessler RC, Barker PR, Colpe LJ, Epstein JF, Gfroerer JC, Hiripi E, et al. Screening for serious mental illness in the general population. Archives of General Psychiatry. 2003;60:184.

34. Australian Bureau of Statistics. 4817.0.55.001 - information paper: Uuse of the kessler psychological distress scale in abs health surveys, australia, 2007-08 Canberra.; 2012.

35. Ferro MA. The psychometric properties of the kessler psychological distress scale (k6) in an epidemiological sample of canadian youth. The Canadian Journal of Psychiatry. 2019;64:647.

36. Peiper N, Clayton R, Wilson R, Illback R. The performance of the $k 6$ scale in a large school sample. Psychological Assessment. 2015;27:228.

37. Chan SM, Fung TCT. Reliability and validity of k10 and k6 in screening depressive symptoms in hong kong adolescents. Vulnerable Children and Youth Studies. 2014;9:75.

38. Furukawa TA, Kessler RC, Slade T, Andrews G. The performance of the k6 and k10 screening scales for psychological distress in the australian national survey of mental health and well-being. Psychological Medicine. 2003;33:357.

39. Cheng SKW, Chong GHC, Chang SSY, Wong CW, Wong CSY, Wong MTP, et al. Adjustment to severe acute respiratory syndrome (sars): Roles of appraisal and post-traumatic growth. Psychology \& Health. 2006;21:301.

40. Lau JTF, Yang X, Tsui HY, Pang E, Wing YK. Positive mental health-related impacts of the sars epidemic on the general public in hong kong and their associations with other negative impacts. Journal of Infection. 2006;53:114.

41. Spriggs M. Understanding consent in research involving children: A handbook for human research ethics committees and researchers: Melbourne, Australia: University of Melbourne; 2010.

42. Carver C. Coping. In: Gellman MD, Turner JR, editors. Encyclopedia of behavioral medicine. New York, NY: Springer New York; 2013. p. 496. 
43. Kobylińska D, Kusev P. Flexible emotion regulation: How situational demands and individual differences influence the effectiveness of regulatory strategies. Frontiers in Psychology. 2019;10.

44. Evans-Whipp T, \& Gasser, C. Adolescents' resilience - Isac annual statistical report 2018 chapter: Australian Government, Australian Institute of Family Studies; 2019.

45. Wright MOD, Masten AS, Narayan AJ. Resilience processes in development: Four waves of research on positive adaptation in the context of adversity. Handbook of resilience in children, 2nd ed. New York, NY, US: Springer Science + Business Media; 2013. p. 15.

46. Dray J, Bowman J, Campbell E, Freund M, Wolfenden L, Hodder RK, et al. Systematic review of universal resilience-focused interventions targeting child and adolescent mental health in the school setting. J Am Acad Child Adolesc Psychiatry. 2017;56:813.

47. Rezapour T, Assari S, Kirlic N, Vassileva J, Ekhtiari H. Enhancing cognitive resilience in adolescence and young adults: A multidimensional approach. In: Croff JM, Beaman J, editors. Family resilience and rrecovery from opioids and other addictions. Cham: Springer International Publishing; 2021. p. 45.

48. Leys C, Arnal C, Wollast R, Rolin H, Kotsou I, Fossion P. Perspectives on resilience: Personality trait or skill? European Journal of Trauma \& Dissociation. 2020;4:100074.

49. Greenaway KH, Kalokerinos EK, Williams LA. Context is everything (in emotion research). Social and Personality Psychology Compass. 2018;12:e12393.

50. Kalokerinos EK, Résibois $\mathrm{M}$, Verduyn P, Kuppens P. The temporal deployment of emotion regulation strategies during negative emotional episodes. Emotion. 2017;17:450.

51. Orben A, Tomova L, Blakemore S-J. The effects of social deprivation on adolescent development and mental health. The Lancet Child \& Adolescent Health. 2020;4:634.

52. Magson NR, Freeman JYA, Rapee RM, Richardson CE, Oar EL, Fardouly J. Risk and protective factors for prospective changes in adolescent mental health during the covid-19 pandemic. Journal of Youth and Adolescence. 2020.

53. Polizzi C, Lynn SJ, Perry A. Stress and coping in the time of covid-19: Pathways to resilience and recovery. Clinical Neuropsychiatry. 2020;17.

54. VicHealth. Community survey of young victorians' resilience and mental wellbeing. Full report: Part a and part b: Melbourne: VicHealth; 2015.

55. Campbell-Sills L, Forde DR, Stein MB. Demographic and childhood environmental predictors of resilience in a community sample. Journal of Psychiatric Research. 2009;43:1007.

56. Senkalfa BP, Sismanlar Eyuboglu T, Aslan AT, Ramasli Gursoy T, Soysal AS, Yapar D, et al. Effect of the covid-19 pandemic on anxiety among children with cystic fibrosis and their mothers. Pediatric Pulmonology. 2020. 